\title{
KAMPANYE PROTOKOL KESEHATAN DAN BUDIDAYA HIDROPONIK DIMASA PPKM DARURAT UNTUK PENGUATAN MASYARAKAT
}

\author{
Nustin Merdiana Dewantari, ${ }^{1}$ Dina Estining Tyas Lufianawati ${ }^{2}$ dan Akbar Gunawan ${ }^{3}$ \\ ${ }^{1}$ Program Studi Teknik Industri Fakultas Teknik Universitas Sultan Ageng Tirtaysa \\ ${ }^{2}$ Program Studi Teknik Elektro Fakultas Teknik Universitas Sultan Ageng Tirtayasa \\ ${ }^{3}$ Program Studi Teknik Industri Fakultas Teknik Universitas Sultan Ageng Tirtaysa \\ E-mail: nustinmd@untirta.ac.id
}

\begin{abstract}
ABSTRAK. Pemerintah memutuskan untuk menerapkan aturan Pemberlakuan Pembatasan Kegiatan Masyarakat (PPKM) Darurat pada tanggal 03-20 Juli 2021. Pemberlakuan PPKM Darurat dilakukan untuk mengurangi penyebaran COVID-19. Namun, hal tersebut memberikan dampak negatif yaitu berkurangnya pendapatan sebagian masyarakat di Kota Serang. Tujuan dari pengabdian ini adalah untuk meningkatkan perekonomian masyarakat Kasemen dengan tetap menerapkan aturan PPKM. Kegiatan pengabdian dilakukan melalui kampanye protokol kesehatan dan pelatihan budidaya hidroponik. Kampanye protokol kesehatan dan budidaya hidroponik dilakukan dengan membuat video dan pamflet serta pengiriman benih untuk menanam bibit sayur secara hidroponik dengan media botol bekas. Metode pelaksanaan kegiatan terbagi menjadi tahap persiapan, pelaksanaan, dan monitoring. Tahap pelaksanaan dimulai dengan mengadakan pertemuan secara online dengan Lurah Kasemen. Tahap pelaksanaan dilakukan dengan mengirimkan video dan pamflet pola hidup sehat dan budidaya hidroponik. Tahap monitoring dilakukan dengan berkomunikasi melalui aplikasi Whatsapp. Pelaksanaan kegiatan pengabdian ini dapat diterima dengan baik oleh masyarakat, tetapi masih membutuhkan metode monitoring yang lebih tepat sehingga hasil budidaya hidroponik menjadi lebih bagus.
\end{abstract}

Kata kunci: PPKM darurat; Pembatasan Kegiatan Masyarakat; Kampanye Protokol Kesehatan; Hidroponik

ABSTRACK. The government decided to implement the rules for the Enforcement of Emergency Community Activity Restrictions (PPKM) on July 3-20, 2021. The implementation of the emergency PPKM was carried out to reduce the spread of COVID-19. However, this has a negative impact, namely the reduced income of some people in Serang City. The purpose of this service is to improve the economy of the Kasemen community while still applying the PPKM rules. Service activities are carried out through health protocol campaigns and hydroponic cultivation training. Health protocol campaigns and hydroponic cultivation are carried out by making videos and pamphlets as well as sending seeds to grow vegetable seeds hydroponically using used bottle media. The method of implementing the activities is divided into the preparation, implementation, and monitoring. The implementation phase begins with holding an online meeting with the Kasemen Village Head. The implementation stage is carried out by sending videos and pamphlets on healthy lifestyles and hydroponic cultivation. The monitoring stage is carried out by communicating through the Whatsapp application. The implementation of this service activity can be well received by the community, but it still requires a more precise monitoring method so that the results of hydroponic cultivation are better

Key Words: Emergency PPKM; Restrictions on Community Activities; Health Protocol Campaign; Hydroponics

\section{PENDAHULUAN}

Pemberlakuan pembatasan kegiatan masyarakat (PPKM) darurat mulai berlaku pada tanggal 03-20 Juli 2021, PKKM darurat ini meliputi pembatasan-pembatasan aktivitas masyarakat yang lebih ketat dari pada yang selama ini telah berlaku sebelumnya seperti pembatasan sosial berskala besar (PSBB), pemberlakuan pembatasan kegiatan masyarakat (PPKM) Jawa- Bali dan PKKM Mikro (Kompas.com) dan setelah PPKM darurat ini pemerintah memperpanjang menjadi PPKM Level 4 yang berlaku sampai tanggal 16 Agustus 2021.

Kasus Covid-19 yang beberapa waktu lalu mengalami peningkatan membuat pemerintah mengambil keputusan dan strategi dengan diberlakukannya PPKM yang merupakan singkatan dari pemberlakuan pembatasan kegiatan masyarakat, PPKM dirasakan sulit oleh beberapa kalangan masyarakat karena seperti artinya sendiri PPKM membatasi gerak masyarakat, adapun beberapa aturan dari PPKM darurat adalah pelaksanaan kegiatan belajar-mengajar dilakukan secara daring, pelaksanana kegiatan non esensial diberlakukan $100 \%$ secara bekerja dirumah, pelaksanaan kegiatan sektor esensial seperti penanganan bencana, logistik, semen dan bahan bangunan dapat beroperasi $100 \%$ namun hanya staff bahkan ada yang mencapai $25 \%$ hanya staff, dengan pemberlakuan PPKM darurat ini masyarakat yang bekerja disektor-sektor tadi ada yang diminta untuk berhenti bekerja secara sementara, dirumahkan dan masyarakat seperti pedagang tidak boleh berjualan lebih dari pukul 21.00 untuk menghindari kerumunan. Hal ini menyebabkan masyarakat mengalami kekurangan bahkan kehilangan pendapatan.

Kesehatan pada masa pandemi harus benarbenar dijaga, pola hidup baru harus diterapkan, karena hal yang baru, lumrahnya akan sulit dipahami sehingga perlu disosialisasikan dan dikampanyekan agar masyarakat mengetahui dan menjadi terbiasa 
melakukannya. Disamping itu perkembangan teknologi bertanam semakin hari semakin baik, upaya yang dilakukan oleh masyarakat baik lembaga maupun perorangan untuk membantu mengatasi permasalahan, salah satunya dengan hidroponik, hidroponik adalah menanam tanpa tanah, melainkan air sebagai medianya (Ambarwati \& Abidin, 2021). Pola tanam hidroponik ini tepat dilakukan pada masa pandemi karena dapat dijangkau oleh semua kalangan, khususnya dapat menjadi jalan keluar bagi yang memiliki lahan sempit dan tidak membutuhkan modal atau biaya yang besar, dapat pula memanfaatkan limbah yang ada dirumah sebagai tempat menanamnya.

Oleh karena itu perlunya peran serta masayarakat sekolah dalam mengkapanyekan pola hidup baru dan ketahanan pangan di masa pandemi khususnya dimasa PPKM darurat ini. Peran serta masyarakat sekolah dalam mengkampanyekan pola hidup baru seperti pola hidup sehat di masa pandemi dan kegiatan-kegiatan yang bisa dilakukan dimasa PPKM darurat, cara membuat handsanitizer dari bahan alami dll diharapkan dapat membantu pemerintah setempat dalam menekan angka positif.

\section{METODE}

Kegiatan ini dilakukan dilaksanakan di Kampung Bebojong, Kelurahan Kasemen, Kecamatan Kasemen, Kota Serang, Banten. Teknis pelaksanaan pengabdian masyarakat ini yaitu dengan membuat video dan pamplet yang disebarkan kepada masyarakat dengan pola penyerahan kepada Ketua RT Kampung Bebojong serta perangkat desa dengan mematuhi protokol kesehatan yang kemudian akan disalurkan lagi kepada warga desa. Kegiatan ini diselenggarakan selama 1 bulan mulai dari 17 Juli 2021 - 18 Agustus 2021. Tahap persiapan dimulai dengan mengadakan pertemuan secara online dengan Kepala Kelurahan Kasemen untuk membicarakan terkait kegiatan yang akan dilakukan, kemudian meminta izin serta meminta nomor kontak ketua RT Bebojong dan membuat whatsapp group, tahap pelaksanaan dilakukan dengan mengirimkan video dan pamphlet terkait pola hidup sehat dan ketahanan pangan di masa PPKM darurat, praktek penanaman hidroponik dilakukan dengan cara mengirimkan bibit kepada ketua RT Bebojong dan masyarakat dapat mempraktekannya dirumah melalui video yang dikirimkan di whatsapp grup, dengan adanya whatsapp grup tersebut masyarakat dapat berdiskusi terkait dengan kegiatan pengabdian yang dilakukan sebagai bagian dari tahap monitoring.

\section{HASIL DAN PEMBAHASAN}

Kegiatan dilakukan pada tanggal 17 Juli 2021 - 18 Agustus 2021 di Kampung Bebojong RT.01 RW. 12 Kelurahan Kasemen, Kota Serang, Kegiatan dimulai dengan berkordinasi dengan pemerintahan setempat tingkat kelurahan yaitu dengan Lurah Kasemen, kordinasi dilakukan melalui pertemuan secara online.

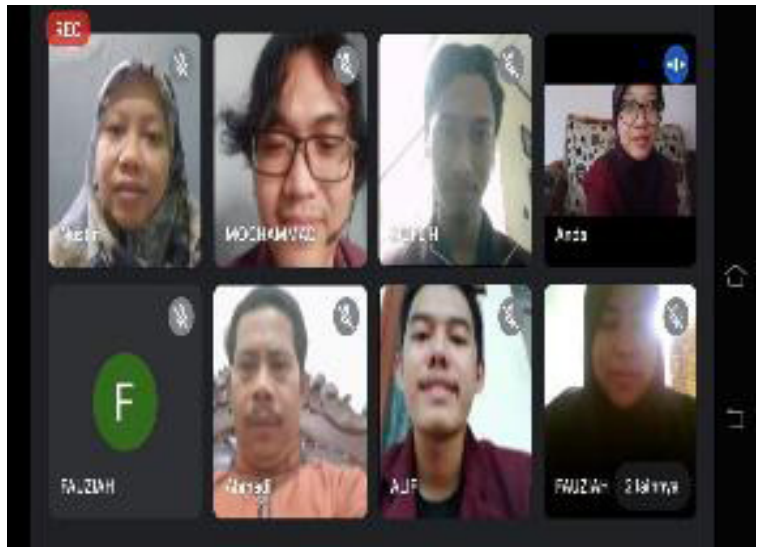

Gambar 1. Pembukaan acara dan Diskusi dengan Kepala Kelurahan Kasemen

Telah disepakati beberapa program kerja dan teknis kegiatan yang akan mendukung kegiatan pengabdian yaitu membuat dan membagikan video protokol kesehatan serta video tutorial cara membuat hidroponik sederhana dengan menggunakan botol plastik bekas. Serta memberikan alat dan bahan kepada masyarakat sekitar yang ada di Desa Bebojong, dan dilakukan monitoring setiap minggu nya untuk melihat perkembangan hidroponik.
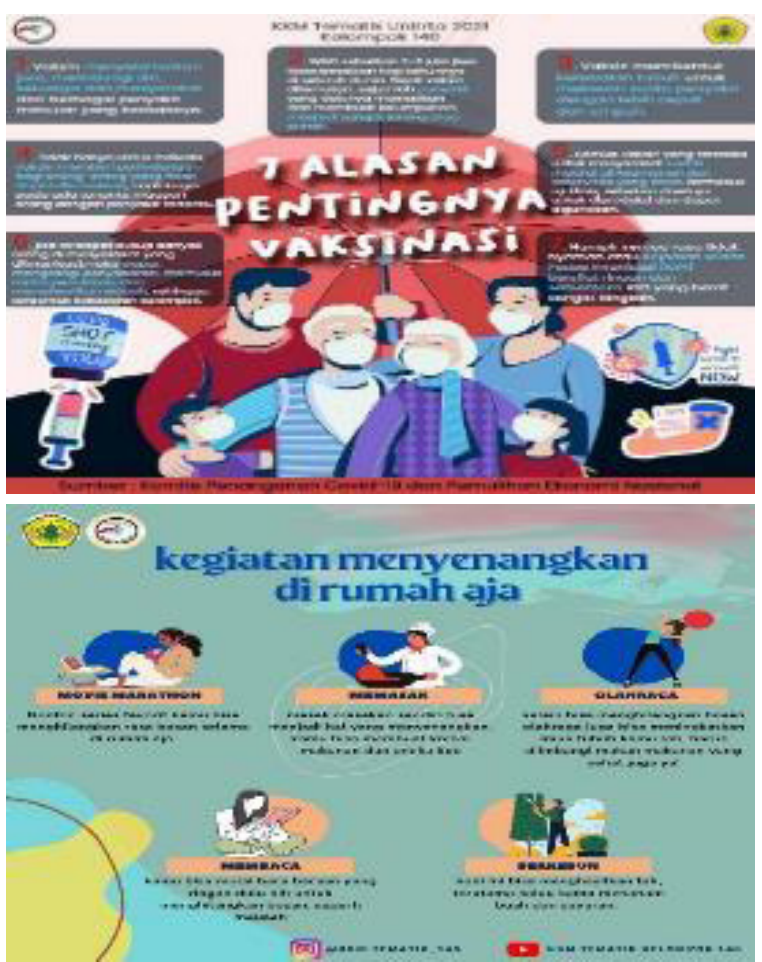

Gambar 2. BeberapaKegiatan dan video Kampanye Protokol Kesehatan di Masa PPKM Darurat 
Gambar diatas adalah beberapa contoh kampanye protokol kesehatan yang dibuat, kampanye ini dituangkan dalam bentuk poster dan video, sedangkan bibit yang disebutkan diatas ada pada gambar 3 dibawah ini

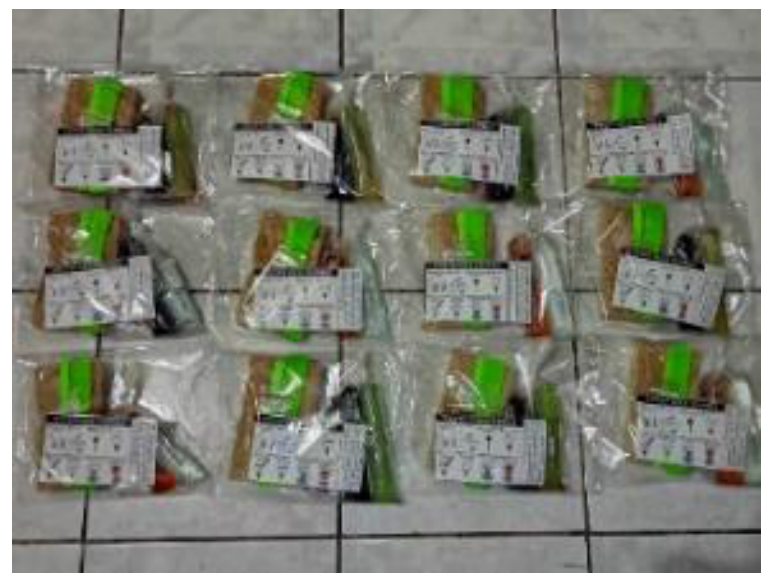

Gambar 3. Bibit untuk Tanam Hidroponik

Tanggapan masyarakat terhadap tanam hidroponik cukup baik, dimana masyarakat memiliki keinginan mencoba mempraktekkan, salah satu hasil tanam masyarakat ada pada gambar dibawah ini. Harapannya masyarakat dapat mengaplikasikan hidroponik secara berkelanjutan, Rimbawani dan Hidayat (2020) mengatakan pada hasil pengabdiannya memang diperlukan upaya sosialisasi hidroponik kepada masyarakat di Sidoarjo agar lebih mengenal lagi.

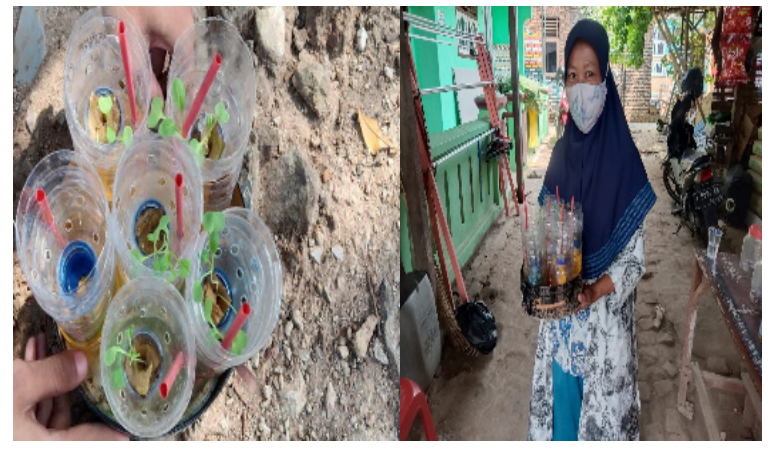

Gambar 4. Hasil Tanam Hidroponik salah satu warga

Pengabdian masyarakat dengan tema protokol kesehatan serta ketahanan pangan juga telah dilakukan oleh beberapa kelompok masyarakat sekolah seperti (Milla, A, N. Nurbaiti, N. Ramadanti, L. Maulana, M. Blesenki, 2020), dengan hasil penerapan protokol kesehatan dapat meningkatkan pemahaman masyarakat terhadap pandemi Covid-19, adapula yang menciptakan alat pemberian nutrisi otomatis pada hidroponik yang dilakukan oleh (Ambarwati dan Abidin, 2021). Kampanye kesehatan dalam bentuk media tulisan juga dilakukan oleh Andriyansyah dkk (2020), hasil yang didapatkan dari kegiatan tersebut masyarakat menjadi memiliki kesadaran terhadap pentingnya mencuci tangan dimasa pandemi.

\section{SIMPULAN}

Kegiatan kampanye protokol kesehatan dan ketahanan pangan budidaya hidroponik sangat dibutuhkan pada masa PKKM darurat, lamanya pandemi yang menyerang membuat masyarakat lelah dan terkadang mengabaikan protokol kesehatan, apalagi dengan meningkatnya kasus pandemi setahun belakangan ini dan diterapkannya PPKM darurat membuat pembatasan beberapa kegiatan masyarakat dalam beraktivitas. Kegiatan tanam hidroponik dengan menggunakan botol minum bekas dapat dikembangkan lebih baik kedepannya dengan menggunakan metode monitoring yang tepat sehingga hasil budidaya hidroponik menjadi lebih bagus serta dapat menjadi tambahan pendapatan bagi masyarakat.

\section{UCAPAN TERIMA KASIH}

Terima kasih penulis ucapkan kepada mahasiswa kuliah kerja mahasiswa kelompok 140 tahun 2021 univeristas Sultan Ageng Tirtayasa, Muflih Nurhakim, Fauziah Nur Surya, M. Falwa Alifian, Grace G. Lopulalan, Alif F. Febrian, Dini Prambandani, dan Skolastika Kirana K.

\section{DAFTAR PUSTAKA}

Ambarwati, D., \&Abidin, Z. (2021). Rancang Bangun Alat Pemberian Nutrisi Otomatis Berdasarkan Konduktivitas Air pada Budidaya Hidroponik. Jurnal Teknologi dan Sistem Informasi (JTSI), 2(1), 29-34

Andriyansyah, M. F., R, D. A., Margarettha, V., \& M, M. I. (2020). Kampanye Pentingnya Himbauan Mencuci Tangan Melalui Media Pamflet Di Masa Pandemi Covid-19. Jurnal Pembelajaran Pemberdayaan Masyarakat, 1(4), 294-299. Retrieved from http://www. riset.unisma.ac.id/index.php/JP2M/article/ view/8823/7624

https://money.kompas.com/read/2021/07/10/092118826/ ppkm-adalah-singkatan-dari-perberlakukanpembatasan-kegiatan

Milla, A, N. Nurbaiti, N. Ramadanti, L. Maulana, M. Blesenki, K. (2020). Pelatihan Penerapan Protokol Kesehatan, Pembuatan Handsanitizer Alami dan Ketahanan Pangan Keluarga di Masa Pandemi COVID-19. JMM(Jurnal Masyarakat Mandiri), 4(5), 1018-1029.

Rimbawani, V. (2020). Pendampingan Masyarakat Candi dalam Budidaya Tanaman Sawi dengan Metode Hidroponik di Kabupaten Sidoarjo. SOEROPATI, 2(2), 167-176 